\title{
ESTIMATIVA DO GANHO GENOTÍPICO POR MEIO DA SELEÇÃO EM GERAÇÃO SEGREGANTE DE AVEIA
}

\section{ESTIMATION OF GENOTYPIC GAIN THROUGH SELECTION IN SEGREGATING GENERATIONS OF OAT}

\author{
Ivandro BERTAN ${ }^{1}$ \\ Andreomar José KUREK² \\ Fernando I. F. de CARVALHO ${ }^{3}$ \\ Isidoro Carlos ASSMANN² \\ Giovani Olegário da SILVA 4 \\ Maicon Luiz COSSA ${ }^{4}$
}

\begin{abstract}
RESUMO
A seleção de genótipos superiores busca explorar ao máximo a variância genética aditiva e, com isso, atribuir aos caracteres selecionados, no próximo ciclo de seleção, um maior potencial. Para isso, é interessante que o melhorista conheça a eficiência que pode ser alcançada quando da utilização de um método de seleção em populações segregantes. Assim, o presente trabalho foi proposto com o objetivo de determinar o ganho genotípico, considerando o diferencial de seleção e a herdabilidade no sentido amplo, estimado em caracteres agronômicos e de qualidade do grão da aveia por meio da seleção realizada na geração $F_{3}$. O experimento foi conduzido no município de Pato Branco, Região Sudoeste do Estado do Paraná, durante o ano de 2001. Os estudos realizados envolveram os caracteres ciclo vegetativo, estatura de planta, peso de panícula, número de grãos/panícola, peso médio de grãos e percentual de cariopse em quatro cruzamentos de aveia branca, UPF 7 X OR 2, UPF 7 X CTC 5, OR 2 X CTC 5 e OR 2 X UPF 18. Os coeficientes de herdabilidade no sentido amplo apresentaram maiores valores para os caracteres ciclo vegetativo $(0,60)$, peso médio de grãos $(0,68)$ e percentual de cariopse $(0,40)$. O diferencial de seleção foi mais expressivo para os caracteres diretamente relacionados a produção de grãos e, juntamente com os valores de herdabilidade no sentido amplo, resultaram em elevado ganho genotípico considerando que os mesmos representaram um único ciclo de seleção.
\end{abstract}

Palavras-chave: Caracteres agronômicos, Herdabilidade, Diferencial de seleção.

\begin{abstract}
In the selection of superior genotypes, it searches to develop the maximum genetic profit and this to attribute the evaluated traits, in the next cycle of selection, a bigger potential. For thus, it is interesting that the breeder by the genetic improvement knows the efficiency that can be reached when any method of selection in segregating populations is used. Thus, the present work was proposed with the objective of determining the genetic profit considering the differential of estimated selection and the heritability in agronomics traits and quality of grain through selection carried out in segregating generations. The experiment was held in Pato Branco, Brazil, in the southwest region of Paraná State, during the year of 2001. The performed studies have involved the traits vegetative cycle, stature of plant, weight of panicle, number of grains/panicle, average weight of grains and percentage of caryopses in four white oats crossing, UPF 7 X OR 2, UPF 7 X CTC 5, OR 2 X CTC 5 e OR 2 X UPF 18. The heritability coefficients have presented bigger values for the traits vegetative cycle $(0,60)$, average weight of grains $(0,68)$ and percentage of caryopses $(0,40)$. The differential selection was more expressive for the traits directly to the production of grains and, together with the values of heritability, have resulted in high genetic profit considering that the same ones represent a single cycle of selection.
\end{abstract}

Key-words: Agronomics traits, Heritability, Differential of selection.

\footnotetext{
${ }^{1}$ Estudante de Agronomia, bolsista do PIBIC/CNPq (2001/2002) no departamento de Fitotecnia do Centro Federal de Educação Tecnológica do Paraná, Unidade de Pato Branco (CEFET - PR, UNED/P.Bco). E-mail: ivandrobertan@yahoo.com.br

${ }^{2}$ Professores do Curso de Agronomia, departamento de Fitotecnia do Centro Federal de Educação Tecnológica do Paraná, Unidade de Pato Branco (CEFET - PR, UNED/P.BCo)

${ }^{3}$ Eng. Agro; (Ph.D), prof. do Depto de Fitotecnia (Fitomelhoramento) da Faculdade de Agronomia Eliseu Maciel, Universidade Federal de Pelotas (FAEM/UFPel).

${ }^{4}$ Estagiários do Curso de Agronomia do Centro Federal de Educação Tecnológica do Paraná, Unidade de Pato Branco (CEFET - PR, UNED/P.Bco).
} 


\section{INTRODUÇÃO}

O alto nível de melhoramento empregado pelos atuais programas de melhoramento na cultura da aveia esta tendo como conseqüências o desenvolvimento de constituições genéticas com elevado potencial produtivo e reduzida variabilidade, restringindo a obtenção de um maior ganho genético. Para Carvalho e Federizzi [1], a interação genótipo $x$ ambiente representa também, grande entrave na seleção para caracteres quantitativos em uma planta de aveia, principalmente em ambientes de alta instabilidade, pela dificuldade de controle da variação de ambiente.

Considerando que a seleção, busca explorar a variância aditiva e, com isso, atribuir aos caracteres selecionados, no próximo ciclo de seleção, maior potencial, é interessante que o melhorista conheça a eficiência que pode ser alcançada na seleção em geração segregante. Para tal, as maiores dificuldades encontradas no processo de seleção está em controlar o efeito da segregação em diferentes caracteres nas primeiras gerações após a hibridação o que pode resultar em maior ou menor ganho genotípico.

$\mathrm{Na}$ determinação do ganho genético, Ronzelli Júnior [2] descreve que o potencial de seleção em uma população e suas respectivas médias é um dado de extrema importância principalmente quando o caráter em seleção é quantitativo, ou seja, governado por vários genes. Tendo estimado os coeficientes de herdabilidade de um caráter, o progresso genético pode ser estimado a partir de uma geração de seleção. O coeficiente de herdabilidade não é uma constante, mas indica a proporção de variação causada por diferenças nos efeitos gênicos aditivos [3].

Neste sentido, o trabalho objetivou avaliar o ganho genotípico em caracteres agronômicos e de qualidade do grão da aveia levando em consideração o diferencial de seleção e a herdabilidade no sentido amplo estimados em geração $F_{3}$ após realização se seleção com base na média mais um desvio padrão, considerando o conjunto dos caracteres simultaneamente.

\section{METODOLOGIA}

O experimento foi conduzido no ano de 2001, no município de Pato Branco, na área experimental do Centro Federal de Educação Tecnológica do Paraná na Unidade de Pato Branco (CEFET-PR/UNED-PB). $A$ adubação realizada foi de $300 \mathrm{~kg} \cdot \mathrm{ha}^{-1}$ de NPK na formulação 05-25-25 e em cobertura foi aplicado 40 $\mathrm{kg} \cdot$ ha $^{-1}$ de N sob a formulação da uréia, por ocasião da emissão da terceira folha.

Seis caracteres: ciclo vegetativo, estatura de planta, peso de panícula, número de grãos/panícola, peso médio de grãos e percentual de cariopse, foram analisados em 2400 plantas de aveia selecionadas em geração $F_{3}$ oriundas de quatro cruzamentos
(UPF 7 X OR 2, UPF 7 X CTC 5, OR 2 X CTC 5 e OR 2 X UPF 18).

Os dados referentes ao ciclo vegetativo e estatura de plantas foram coletados a campo, mediante anotações individuais de cada planta utilizando o afilho principal como referência. Os demais caracteres foram avaliados por ocasião da colheita da panícula principal, quando foram pesados e contados os grãos em laboratório.

A seleção dos genótipos superiores considerou aquelas plantas que apresentaram superioridade para um maior número de caracteres simultaneamente, tendo como base a média mais um desvio padrão e uma pressão de seleção de $5 \%$. Para os caracteres ciclo vegetativo e estatura de planta, selecionaramse plantas enquadradas entre a média e a média mais um desvio padrão, com a finalidade de ajustar essas características de acordo com o tipo desejável considerando as práticas agronômicas na cultura da aveia. Para os demais caracteres selecionaram-se plantas com dados superiores a média mais um desvio padrão, dentro de cada cruzamento.

Para determinação do ganho genotípico, foi utilizada a fórmula $\Delta_{\mathrm{g}}=\mathrm{h}^{2} \times \Delta_{\mathrm{s}}$ desenvolvida por Carvalho [4] onde,

$\Delta_{\mathrm{g}}=$ ganho genético;

$\mathrm{h}^{2}=$ herdabilidade no sentido amplo;

$\Delta_{\mathrm{s}}=$ diferencial de seleção

Para a estimativa da herdabilidade no sentido amplo, os dados referentes aos seis caracteres foram submetidos ao método de regressão Genitor $\left(F_{3}\right)-$ Progênie $\left(\mathrm{F}_{4}\right)$ desenvolvida por Becker [5] apud Carvalho et al. [6] seguindo o modelo:

$Y_{i}=b X_{i}+e_{i}$ onde,

$Y_{i}=$ média da progênie para o caráter; genitor;

$\mathrm{bX}_{\mathrm{i}}=$ observação referente ao caráter no

$\mathrm{e}_{\mathrm{i}}=$ erro experimental

O diferencial de seleção foi estimado a partir da diferença entre a média dos indivíduos selecionados e a média original da população. $O$ modelo proposto no presente estudo para esta estimativa é definido a seguir:

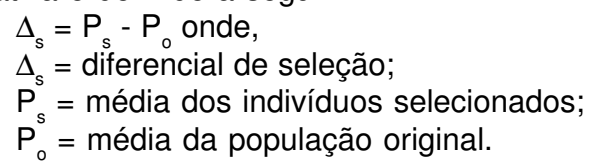

\section{RESULTADOS E DISCUSSÃO}

Conforme os resultados obtidos para os coeficientes de herdabilidade no sentido amplo (Tabela 1), observa-se para os caracteres ciclo vegetativo $(0,60)$, peso médio de grãos $(0,68)$ e percentual de cariopse $(0,40)$ os maiores valores médios. Estes valores estão de acordo com aqueles obtidos na pesquisa de aveia por Marshall e Shaner [7], Wesemberg e Shands [8] e Bunch e Forsberg [9] que encontraram para o caráter peso médio de grãos valores entre 0,71 e 0,89. Já Cabral [10], utilizando 
genitores de menor dissimilaridade genética, encontrou valores menores cuja variação ficou entre 0,27 e 0,60 dos coeficientes de herdabilidade.

Para percentual de cariopse, os resultados encontrados foram de acordo com os obtidos por Ronald et al. [11] e Bunch e Forsberg [9] em que as estimativas de herdabilidade no sentido amplo ficaram entre 0,35 a 0,72 e 0,50 a 0,90, respectivamente, confirmando que o caráter é altamente herdável.

No caráter ciclo vegetativo, Amaral et al. [12] confirmam os resultados obtidos neste trabalho cuja herdabilidade média no experimento conduzido por esses pesquisadores ficou em 0,70.

Todavia, para estatura, peso de panícula e número de grãos/panícula encontrou-se valor baixo de herdabilidade no sentido amplo. Isso se explica por serem caracteres controlados por vários genes e fortemente influenciados pela ação do ambiente. Como o método considera a relação entre o genitor e a progênie, os dados são obtidos em diferentes anos, resultando uma variação nas condições de ambiente. Assim, caracteres qualitativos, ou controlados por poucos genes, não são modificados em igual proporção aos caracteres quantitativos. Sendo assim, a utilização deste método para estimar a herdabilidade requer maior precisão experimental, a fim de diminuir a ação do ambiente sobre a população. Sem influência do ambiente de cultivo no método de estimativa da herdabilidade, Amaral [12] apontou o valor de 0,55 e Dolan et al. [13] de 0,87 para o caráter estatura de planta.

Para peso de panícula, a elevada variância do ambiente proporcionando baixa variação genotípica resultou em valores baixos de herdabilidade. Estes valores estão de acordo com os obtidos no estudo do peso de panícula como estratégia de incremento no rendimento de grãos, realizado por Caierão [14], onde a herdabilidade média estimada foi de 0,32 para diferentes populações no ambiente Pelotas e 0,21 para as mesmas populações em Passo Fundo e Porto Alegre. Já para o caráter número de grãos/panícula, Petr e Frey [15] encontraram valores maiores que os obtidos neste trabalho o que confirma a forte influência do ambiente interferindo nos resultados. A herdabilidade estimada no experimento conduzido por esses pesquisadores foi de 0,74 .

TABELA 1 - Herdabilidade no sentido amplo estimada para os caracteres ciclo vegetativo (C.V.), estatura de planta (E.), peso de panícula (P.P.), número de gãos/panícula (N.G.P.), peso médio de grãos (P.M.G.) e percentual de cariopse (\%Cp) em quatro cruzamentos de aveia. CEFET-PR/Pato Branco, 2002.

\begin{tabular}{|c|c|c|c|c|}
\hline \multirow[b]{2}{*}{ Caracteres } & \multicolumn{4}{|c|}{ CULTIVARES } \\
\hline & UPF 7 X OR 2 & UPF $7 \mathrm{X}$ CTC 5 & OR 2 X CTC 5 & OR 2 X UPF 18 \\
\hline C.V. & 0,47 & 0,66 & 0,48 & 0,78 \\
\hline E. & 0,08 & 0,18 & 0,10 & 0,15 \\
\hline P.P. & 0,01 & 0,06 & 0,00 & 0,01 \\
\hline $\begin{array}{l}\text { P.M.G. } \\
\text { N.G.P. }\end{array}$ & $\begin{array}{l}0,73 \\
0,34\end{array}$ & $\begin{array}{l}0,89 \\
0,01\end{array}$ & $\begin{array}{l}-- \\
-\end{array}$ & $\begin{array}{l}0,40 \\
0,08\end{array}$ \\
\hline \% Cp. & 0,30 & 0,67 & 0,24 & - \\
\hline
\end{tabular}

Para o diferencial de seleção, os resultados obtidos (Tabela 2) confirmam valores baixos para o caráter ciclo vegetativo e em dois cruzamentos valores negativos. Isso se deve ao fato deste caráter ter sofrido rigorosa seleção na geração $F_{2}$ e a seleção nos descendentes $\mathrm{F}_{3}$ ter objetivado manter próximo os valores de ciclo.

Valores consideráveis de diferencial de seleção, foram encontrados para os caracteres relacionados diretamente no rendimento de grãos. O caráter número de grãos/panícula, por exemplo, estimou-se valores entre 14,8 e 32,3 (Tabela 3). Neste caso, considerando ausente a variação na herdabilidade para o caráter $\left(h^{2}=1\right)$, o ganho genético no número de grãos/panícula apresentaria os mesmos valores do diferencial de seleção. Porém a real estimativa do ganho genético só é obtida pela multiplicação da herdabilidade com o diferencial de seleção, como esta apresentado na Tabela 3
Tendo estimado os coeficientes de herdabilidade e estimado os valores do diferencial de seleção (Tabelas 1 e 2, respectivamente), foi possível determinar o real incremento obtido por meio da seleção nos caracteres em estudo. Os resultados encontrados (Tabela 3 ) evidenciam incremento no caráter peso médio de grãos nos quatro cruzamentos avaliados, mediante estimativa do ganho genotípico, cujos valores oscilaram entre 3,57 e $12,5 \%$, sendo considerados elevados para um único ciclo de seleção. Para os caracteres peso de panícula, número de grãos/panícula e percentual de cariopse as estimativas de ganho genotípico também podem ser considerados elevados para uma geração de seleção. No número de grãos/ panícula, os resultados encontrados neste estudo foram semelhantes aos verificados por Bregitzer [16] onde após três ciclos de seleção, o ganho genotípico ficou na ordem de 15,7\%. 
BERTAN , I. et al. Estimativa do ganho genotípico por...

TABELA 2 - Diferencial de seleção (D.S.) estimado para os caracteres ciclo (C.V.), estatura (E.P.), peso de panícula (P.P.), número de grãos/ panícula (N.G.P.), peso médio de grãos (P.M.G.) e percentual de cariopse (\%Cp.) em quatro cruzamentos de aveia. CEFET-PR/UNED-PB, 2002.

\begin{tabular}{|c|c|c|c|c|c|c|c|c|c|c|c|c|}
\hline \multirow{3}{*}{ Caracteres } & \multicolumn{12}{|c|}{ CRUZAMENTOS } \\
\hline & \multicolumn{3}{|c|}{ UPF 7 X OR 2} & \multicolumn{2}{|c|}{ UPF $7 \mathrm{X}$} & \multirow{2}{*}{$\begin{array}{c}\text { TC } 5 \\
\text { D.S. }\end{array}$} & \multicolumn{3}{|c|}{ OR 2 X CTC 5} & \multicolumn{3}{|c|}{ OR 2 X UPF 18} \\
\hline & $\mathrm{X}_{\mathrm{s}}$ & $\mathrm{X}_{0}$ & D.S. & $\overline{X_{s}}$ & $\mathrm{X}_{0}$ & & $\mathrm{X}_{\mathrm{s}}$ & $\mathrm{X}_{\mathrm{o}}$ & D.S. & $\mathrm{X}_{\mathrm{s}}$ & $\mathrm{X}_{0}$ & D.S. \\
\hline C.V. & 88 & 89 & -1 & 80,4 & 81 & $-0,6$ & 89,6 & 86 & 3,6 & 86 & 85 & 1 \\
\hline E.P. & 93 & 86 & 7 & 94,6 & 88 & 6,6 & 97,7 & 91 & 6,7 & 98,9 & 92 & 6,9 \\
\hline P.P. & 2,79 & 1,80 & 0,99 & 228 & 1,49 & 0,79 & 2,3 & 62 & 0,68 & 3,32 & 2,14 & 1,18 \\
\hline $\begin{array}{l}\text { P.M.G. } \\
\text { N.G.P. }\end{array}$ & $\begin{array}{c}0.028 \\
81\end{array}$ & $\begin{array}{c}0,025 \\
56\end{array}$ & $\begin{array}{c}0,004 \\
25\end{array}$ & $\begin{array}{c}0,033 \\
52,3\end{array}$ & $\begin{array}{c}0,031 \\
36\end{array}$ & $\begin{array}{c}0,002 \\
16,3\end{array}$ & $\begin{array}{c}0,031 \\
61,8\end{array}$ & $\begin{array}{c}0,028 \\
47\end{array}$ & $\begin{array}{c}0,003 \\
14,8\end{array}$ & $\begin{array}{c}0,030 \\
94,3\end{array}$ & $\begin{array}{c}0,028 \\
62\end{array}$ & $\begin{array}{c}0,002 \\
32,3\end{array}$ \\
\hline \% Cp. & 71,03 & 69,05 & 1,98 & 74,9 & 70,1 & 4,8 & 78,8 & 75,2 & 3,6 & 72,4 & 70,1 & 2,3 \\
\hline
\end{tabular}

$\mathrm{X}_{\mathrm{S}}=$ média dos indivíduos selecionados; $\mathrm{X}_{0}=$ média da população original

O cruzamento entre UPF $7 \times$ OR 2 , para o caráter número de grãos/panícula, mostrou o maior ganho genotípico $(34,4 \%)$ entre todos os caracteres e nos quatro cruzamentos. Esse valor, pode estar associado a alta herdabilidade que o caráter possui mesmo em geração precoce. No experimento conduzido por Kurek [17], a variação de herdabilidade ficou entre 0,64 e 0,98. Já Wesemberg e Shands [8] obteve valores entre 0,71 e 0,89 . Como o ganho genotípico é calculado utilizando o diferencial de seleção e a herdabilidade em cada caráter, ambos com valores altos nesse experimento, obteve-se desta forma, elevado incremento através da seleção para este caráter. Se repetido o mesmo trabalho de seleção, tendo como base os valores obtidos, em um único ciclo, pode-se chegar a percentuais de ganho genotípico que potencializam o material selecionado a superar, em grande escala, seus genitores.

TABELA 3 - Ganho genotípico estimado para os caracteres ciclo (C.V.), estatura (E.), peso de panícula (P.P.), número de grãos/ panícula (N.G.P.), peso médio de grãos (P.M.G.) e percentual de cariopse (\%Cp.) em quatro cruzamentos de aveia. CEFET-PR/UNED-PB, 2002

\begin{tabular}{lcccccccc}
\hline \multirow{2}{*}{ Caracteres } & \multicolumn{2}{c}{ UPF 7 $\times$ OR 2} & \multicolumn{2}{c}{ UPF 7 $\times$ CTC 5 } & \multicolumn{2}{c}{ OR 2 $\times$ CTC 5 } & \multicolumn{2}{c}{ OR 2 $\times$ UPF 18 } \\
\cline { 2 - 9 } & $\Delta_{g}$ & $\Delta_{g(\%)}$ & $\Delta_{g}$ & $\Delta_{g}(\%)$ & $\Delta_{g}$ & $\Delta_{g}(\%)$ & $\Delta_{g}$ & $\Delta_{g}(\%)$ \\
\hline C.V. & $-0,47$ & 0,52 & 0,04 & 0,05 & 1,7 & 1,98 & 0,78 & 0,92 \\
E. & 0,60 & 0,70 & 1,20 & 1,36 & 0,60 & 0,66 & 1,00 & 1,10 \\
P.P. & 0,01 & 0,67 & 0,05 & 3,35 & 0,00 & 0,12 & 0,01 & 0,47 \\
P.M.G. & 0,003 & 12,50 & 0,002 & 6,45 & - & - & 0,001 & 3,57 \\
N.G.P. & 8,60 & 34,40 & 0,08 & 0,22 & - & - & 2,45 & 3,95 \\
$\%$ Cp & 0,60 & 0,87 & 3,20 & 4,56 & 0,90 & 1,20 & - & - \\
\hline
\end{tabular}

De fato, o ganho genético é muito maior quando calculado nas primeiras gerações em que o grau de segregação é alto e onde há maior variabilidade na população. Em gerações mais avançadas a margem de ganho genético, por geração, é diminuída onde praticamente a única variação que ocorre é aquela ocasionada pelo efeito do ambiente.

\section{CONCLUSÃO}

Houve ganho genotípico em todos os caracteres diretamente relacionados à produção de grãos com a seleção pelo método utilizado. Com isso, o método de seleção com base na média mais um desvio padrão, considerando o conjunto dos seis caracteres pode ser considerado eficiente na seleção de genótipos superiores em gerações segregantes. 


\section{REFERÊNCIAS BIBLIOGRÁFICAS}

1. CARVALHO, F.I.F., FEDERIZZI, L. C. Evolução da Cultura de Aveia no Sul do Brasil. In: Reunión de Especialistas Nacionales en Avena, Cebada y Triticale del Cono Sur. Montevideo: IICA - PROCISUR, 1993.

2. RONZELLI JÚNIOR, P. Melhoramento Genético de Plantas. Graffice Ed. Graf. Ltda. Curitiba, 1996. 219p.

3. GARDNER, E.J., SIMMONS, M.J., SNUSTAD, D.P. Principles of Genetics. 8. ed. Londres: John Wiley \& Sons INC., 1991.

4. CARVALHO, F.I.F. Genética quantitativa. In: OSÓRIO, E.A. Trigo no Brasil. São Paulo: Fundação Cargil, 1982. v. 1, cap. 3, p. 63-94.

5. BECKER, W.A. Manual of quantitative genetics. 4 ed. Pullman: Washington, 1984. $195 \mathrm{p}$.

6. CARVALHO, F.I.F., SILVA, S.A., KUREK, A.J., MARCHIORO, V.S. Estimativas e implicações da herdabilidade como estratégia de seleção. Pelotas: UFPel. Ed. Universitária, 2001. 99p.

7. MARSHALL, H.G., SHANER, G.E. Genetics and inheritance in oat. In: MARSHALL, H.G., SORRELS, M.E. Oat Science and Technology. Madison, p.756-775, 1992.

8. WESEMBERG, D.M., SHANDS, H.L. Heritability of oat caryopsis percentage and other grain quality components. Crop Science, Madison, v.13, p.481-484, 1973.

9. BUNCH, R.A., FORSBERG, R.A. Relationships between groat percentage and productivity in an oat head-row series. Crop Science, Madison, v.29, p.1409-1411, 1989.

10. CABRAL, C.B. Herança de caracteres morfológicos para qualidade física do grão em aveia (Avena sativa L.). Porto Alegre, 2000. 69p. Dissertação (Mestrado em Fitotecnia - Plantas de Lavoura) - UFRGS, 2000.

11. RONALD, P.S., BROWN, P.D., PENNER, G.A., BRÛLÉ-BABEL, A., KIBITE, S. Heritability of hull percentage in oat. Crop Science, Madison, v.39, p.52-57, 1999.

12. AMARAL, A.L.; CARVALHO, F.I.F.; FEDERIZZI, L.C.; MITTELMANN, A., PANDINI, F. Estimativa da herdabilidade para os caracteres adaptativos ciclo e estatura de planta em aveia. Ciência Rural, Santa Maria, v.26, n.1, p.33-37, 1996.

13. DOLAN, D.J., STUTHMAN, D.D., KOLB, F.L., HEWINGS, A.D. Multiple trait selection in a recurrent selection population in oat (Avena sativa L.). Crop Science, Madison, v.36, p.1207-1211, 1996.

14. CAIERÃO, E. Peso de panícula como estratégia de incremento no rendimento de grãos em aveia, a partir da seleção indireta. Pelotas, 2000. 60p. Dissertação (Mestrado em Agronomia - Fitomelhoramento) - Faculdade de Agronomia Eliseu Maciel, UFPel, 2000.

15. PETR, F.C., FREY, K.J. Genotypic correlations, dominance and heritability of quantitative characters in oats. Crop Science, Madison, v.6, p.259-262, 1966 .

16. BREGITZER, P.P., STUTHMAN, D.D., McGRAW, R.L., PAYNE, T.S. Morphological changes associated with three cycles of recurrent selection for grain yield improvement in oat. Crop Science, Madison, v.27, p.165-168, 1987.

17. KUREK, A.J. Estimativa da herança e correlações entre caracteres agronômicos e de qualidade de grãos em aveia hexaplóide cultivada. Pelotas: UFPel, 2001, 87p. Dissertação (Mestrado em agronomia - Fitomelhoramento), Fac. de Agronomia, UFPel, Pelotas, RS, 2001. 